\title{
A Q-Methodology Study of Patients' Subjective Experiences of TIA
}

\author{
Laura Spurgeon, ${ }^{1}$ Glyn Humphreys, ${ }^{2}$ Gill James, ${ }^{3}$ and Cath Sackley ${ }^{1}$ \\ ${ }^{1}$ Department of Primary Care, University of Birmingham, Edgbaston, Birmingham B15 2TT, UK \\ ${ }^{2}$ Department of Experimental Psychology, University of Oxford, OX1 3UD, UK \\ ${ }^{3}$ Department of Nursing and Physiotherapy, University of Birmingham, Edgbaston, Birmingham B15 2TT, UK
}

Correspondence should be addressed to Laura Spurgeon, lcs838@bham.ac.uk

Received 1 March 2012; Revised 17 April 2012; Accepted 19 April 2012

Academic Editor: Chelsea S. Kidwell

Copyright (C) 2012 Laura Spurgeon et al. This is an open access article distributed under the Creative Commons Attribution License, which permits unrestricted use, distribution, and reproduction in any medium, provided the original work is properly cited.

\begin{abstract}
Background. An expanding body of research has focused on a range of consequences of TIA. However, no work has been conducted on the patient's subjective experience of TIA. Aim. To capture patients' first-hand experiences of TIA. Method. Using Qmethodology which employs both qualitative and quantitative approaches, 39 statements relating to the clinical, physical, affective, and psychological impact of TIA were distilled from the literature and from patient narratives. Consistent with conventional Qmethodology, a purposive sample of twentythree post-TIA patients sorted these statements into a normally-distributed 39-cell grid, according to the extent to which each represented their experience of TIA. Results. Casewise factoranalysis was conducted on the sorted statements. Eight factors emerged which were labelled: lack of knowledge/awareness of TIA; life impact; anxiety; interpersonal impact; depression; physical consequences; cognitive avoidance/denial; constructive optimism. Conclusions. Five of the eight factors confirmed existing research on the impact of TIA, but three new issues emerged: deep-seated anxiety, denial and constructive optimism. The emerging perspectives highlight areas to target in the management of TIA and could inform health education messages, patient information, individualised caremanagement, and enhancement of coping strategies. With development, the findings could be used as a basis for psychometric risk assessment of TIA patients.
\end{abstract}

\section{Introduction}

TIA is defined as "a transient episode of neurological dysfunction caused by focal brain, spinal cord, or retinal ischemia, without acute infarction. Patients with TIAs are at high risk of early stroke" [1, page 2276]. Symptoms typically last less than an hour [2]. Because of diagnostic imprecision [3], incidence and prevalence figures are unreliable, but an estimated 0.66 TIAs per 1000 population (between 50,000 and 60,000) occur per annum [4]. Around 20\% will go on to have a stroke within a month, with the greatest risk being within the first 72 hours [5]. Therefore, early postTIA intervention is essential in order to offset stroke and has been shown to be both clinically and fiscally effective [6]. Despite this, the provision of post-TIA care is limited and where it does exist, its uptake by patients is low [7].
One explanation for this shortfall may be the implicit assumption of both service providers and patients that TIA is benign, minor and has little need for emergency intervention [8]. Even for those patients who do not go on to have major stroke, the consequences of TIA may be significant. Yet, relative to stroke, the research on the sequelae of TIA is limited, but that which has been conducted has shown that TIA patients may experience long-term physical/clinical problems, functional impairments $[8,9]$, affective and cognitive disorders [10-13], reduced quality of life [12, 14], and impaired physical and occupational functionality $[12,14,15]$. Together, the evidence makes an unassailable case for effective management of TIA.

It has been suggested with regard to stroke rehabilitation that the patient's subjective experience is critical for their engagement in poststroke rehabilitation and adaptation, although capturing these experiences may be difficult 
[16]. Some work has been conducted on stroke patients' experiences, but this has tended to use either established psychometric questionnaires [17], which therefore prescribe the issues to be investigated, or alternatively open-response approaches which have focused on a single element of the poststroke experience, such as dysarthria [18], or fatigue [19]. Such studies, therefore, define the area of interest and the outcomes to be measured and consequently are not a comprehensive account of the spectrum of factors that may be perceived to be pertinent by patients themselves. However, despite the potential value to the rehabilitation process of identifying patients' subjective experiences, no similar work has been conducted with TIA patients. The well-documented interdependence between psychological and physical state [20], together with the acknowledged importance to rehabilitation of the patient's first-hand experience, suggests that further investigation of TIA patients' perspectives may be indicated. Such research could potentially offer some insight into the psychological consequences of TIA and hence inform effective and individualised post-TIA management in accordance with the recommended guidelines [16]. This study, therefore, aimed to capture patients' experiences of TIA and its subsequent impact, using a Q-methodology research protocol which combined the rigour of quantitative data with the richness of qualitative data.

\section{Methodology}

2.1. Design. Standard Q-methodology protocol was adopted [21-23]. This technique is highly applicable to healthcare research, although it has not been used with TIA or stroke. Its use of rigorous and established quantitative analysis of rich subjective data makes the technique epistemologically acceptable to a range of healthcare professionals. Q-methodology captures subjective experiences and then organises these into common perspectives or stories, which can then be used in a variety of ways, for example, to inform treatment-planning, information provision, and as the basis of risk-assessment tools. Q-methodology does not require large or representative samples, since the aim is to select participants who will potentially reflect a range of views and experiences. Because the task involves sorting prepared statements, the technique offsets many of the methodological problems faced by patients when attempting to introspect and report their own personal experiences [16].

Participants rank-order a set of statements about the research topic, according to the degree to which each statement reflects their own experience or viewpoint. The statements are sorted into a grid arranged as a normal distribution curve, with one pole of the grid representing statements that are "totally unlike own experience/view," through "neither like nor unlike own experience/view," to "very like own experience/view," at the opposing pole (see Figure 1). Because the grid complies with a normal distribution format, a prescribed number of statements must be allocated to each part of it. The sorted statementsets are then factor analysed casewise (as opposed to the

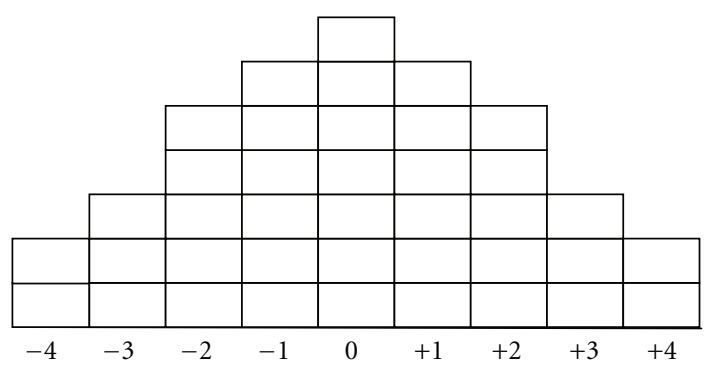

FIGURE 1: Blank Q-sort grid showing rank orderings from -4 (most unlike my own experience) to +4 (most like my own experience).

standard itemwise factoring), to generate clusters of similar perspectives-in this case, experiences of TIA.

The Q-method protocol involves four stages namely:

(1) development of a set of statements "the concourse,"

(2) sorting the concourse statements into a normal distribution grid,

(3) analysis of the sorted grids using casewise factor analysis,

(4) interpretation of the results.

2.2. Ethics. None of the participants was currently a National Health Service patient, so approval was obtained through the University of Birmingham ethics process.

2.3. Concourse Development. As the concourse must capture the range of participants' experiences, (in this case, of a TIA), a variety of sources was used to develop the concourse statements. Here, a thematic review of (a) the relevant literature; (b) semistructured interview narratives from five TIA patients regarding their experiences of TIA; (c) internet TIA self-help chatrooms was conducted using thematic network analysis [24]. This generates three hierarchical levels of information-basic themes (the information that is derived from the narrative/text data); organising themes, which are clusters of similar basic themes; global themes (overarching categories that include all the basic and organising themes). Applied to the current study, four global themes were derived-cognitive, physical, psychosocial, and practical problems; a simplified example of the three-tier hierarchical analysis is presented in Figure 2.

From these distilled themes, 39 statements were developed independently by three researchers, which were individually distinct (therefore avoiding replication of concepts), unambiguous, noncontentious, and a comprehensive reflection of the issues affecting TIA patients [22]. The statements are presented in Table 1.

Each statement was printed on a separate card; the cards were then randomly arranged, and each was numbered on the reverse. A 39-cell normal-distribution grid was constructed to accommodate the statements and ranged from -4 (totally unlike my own experience) to +4 (very like my own experience). The statements and procedure 


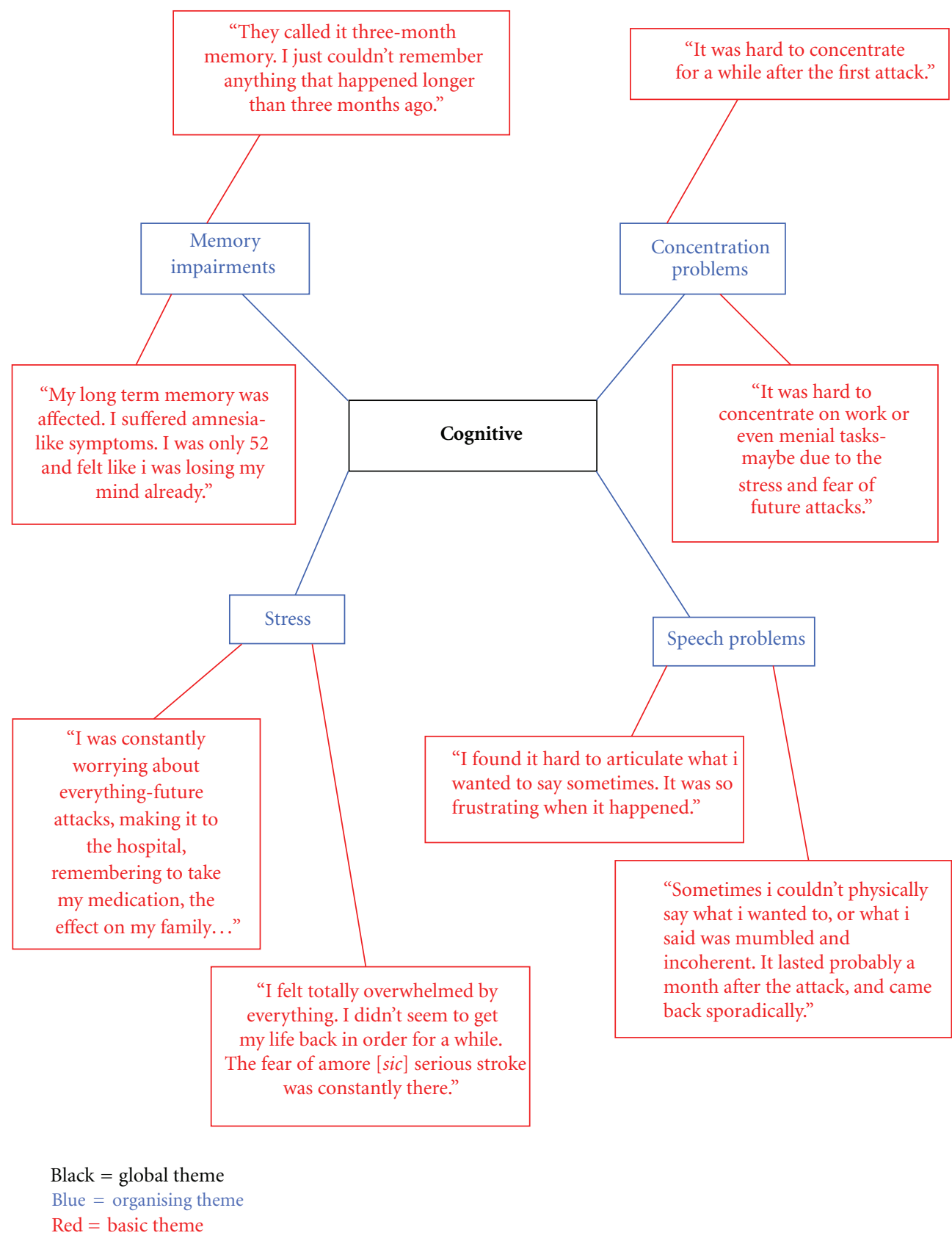

Figure 2: Simplified thematic analysis of cognitive problems post-TIA (selected basic themes in red outer boxes, organising themes in blue, global theme in black).

were piloted with three TIA patients to check for clarity and viability, prior to starting the main study.

2.4. Sample. Twenty-three participants, who had experienced TIA within the previous two years, but without subsequent stroke, were selected. All were competent at English, sufficiently fit to participate, and able to provide informed consent. The participants were identified via the Stroke Network and from a panel of volunteers attached to the University of Birmingham. As neither large nor random samples are a requirement of Q-methodology, this small purposive sample of 23 TIA patients was consistent with the recommended protocol [22]. Sample details are provided in Table 2.

2.5. Procedure. The pack of 39 cards, the Q-sort grid, and an instruction sheet were given to individual participants. Each participant read every individual statement and then sorted these into three preliminary piles, without constraint at this stage on the number of cards in each pile; the three piles were nominally labelled: "totally unlike my own experience of TIA," "neither like nor unlike my own experience of TIA" and "very like my own experience of TIA." From these initial sorts, the participant was then asked to review the statements 
TABLE 1: The concourse statements.

\begin{tabular}{|c|c|c|c|}
\hline $\begin{array}{l}\text { Statement } \\
\text { number }\end{array}$ & Statement & $\begin{array}{c}\text { Statement } \\
\text { number }\end{array}$ & Statement \\
\hline 1 & I was thankful I had been given this warning sign & 21 & $\begin{array}{l}\text { I didn't realise how much I'd been affected by what } \\
\text { happened }\end{array}$ \\
\hline 2 & $\begin{array}{l}\text { Not being able to speak or communicate for a while } \\
\text { afterwards was particularly upsetting }\end{array}$ & 22 & I became very depressed after it happened \\
\hline 3 & $\begin{array}{l}\text { Since what happened, my head feels fuzzy and I can't } \\
\text { think clearly }\end{array}$ & 23 & My memory was affected afterwards \\
\hline 4 & People thought I was making a fuss about nothing & 24 & Every part of my life was affected by what happened \\
\hline 5 & $\begin{array}{l}\text { The healthcare staff didn't know much about my } \\
\text { condition so didn't take it seriously }\end{array}$ & 25 & $\begin{array}{l}\text { I let what happened take over my life and control } \\
\text { what I did }\end{array}$ \\
\hline 6 & $\begin{array}{l}\text { I kept thinking how lucky I had been not to have had a } \\
\text { full stroke }\end{array}$ & 26 & The impact of what happened went on for some time \\
\hline 7 & $\begin{array}{l}\text { Afterwards I was nervous about going out socially } \\
\text { because I felt awkward and embarrassed }\end{array}$ & 27 & I didn't feel any different afterwards \\
\hline 8 & I was back doing normal things shortly afterwards & 28 & $\begin{array}{l}\text { I was scared about the long-term effects of what } \\
\text { happened }\end{array}$ \\
\hline 9 & My friends seemed to avoid me afterwards & 29 & I felt overwhelmed by anxiety afterwards \\
\hline 10 & The numbness in my face afterwards really worried me & 30 & I felt my family was a bit irritated with me afterwards \\
\hline 11 & The health care staff really knew what to do to help me & 31 & $\begin{array}{l}\text { What happened made me re-think what's important } \\
\text { to me }\end{array}$ \\
\hline 12 & I felt really angry and resentful afterwards & 32 & $\begin{array}{l}\text { I found the weakness in my arm afterwards very } \\
\text { distressing }\end{array}$ \\
\hline 13 & I felt that I was somehow to blame for what happened & 33 & I lost all confidence in my body afterwards \\
\hline 14 & When it happened I didn't really know what it was & 34 & $\begin{array}{l}\text { Afterwards, I felt really frustrated about what I could } \\
\text { and couldn't do }\end{array}$ \\
\hline 15 & After it happened, I kept thinking I would have a stroke & 35 & I felt I was a bit of a burden on my family afterwards \\
\hline 16 & Afterwards I felt OK, but others noticed a change in me & 36 & When it happened, I felt reminded of my age \\
\hline 17 & I really appreciated my family a lot more afterwards & 37 & I improved my lifestyle as a result of what happened \\
\hline 18 & I felt I was wasting the doctor's time when it happened & 38 & Afterwards, I was tired all the time \\
\hline 19 & $\begin{array}{l}\text { I have no idea what to do in order to prevent it } \\
\text { happening again }\end{array}$ & 39 & I couldn't sleep for worry afterwards \\
\hline 20 & I was very withdrawn afterwards & & \\
\hline
\end{tabular}

and then to refine their arrangement by allocating them to the ordinal categories in the 39-cell grid according to the extent to which each reflected his/her own experience. When the participant was satisfied with the allocation, the number of each statement (printed on the reverse of each card-see Subsection 2.3) was recorded in the appropriate cell in the grid; the card numbers in each cell constituted the data (or Q-sorts) for analysis. Figure 3 provides an example.

The sorts were both anonymous and confidential, though biographical details were collected. In addition, each participant was asked to record the reasons for selecting those statements which (a) best reflected his/her own experience and (b) least reflected it. These narrative accounts were then used to elaborate and interpret the stories that emerged.

\subsection{Data Analysis and Results}

2.6.1. Data Analysis. A proprietary software package (PQMethod) was used to analyse the grids. Each participant's Q-sort was entered into the database, by recording the number of the card allocated to each of the 39 cells. In this way, 23 Q-sets of data were entered. PQMethod was then used to analyse the sorts. The basis of Q-sort statistics is factor analysis, an established (though highly complex) mathematical data-reduction technique designed to expose underlying groupings or patterns in the data, known as factors. Conventional factor analysis analyses a dataset by clustering variables into factors, according to the degree of association between the variables; with Q-sort, the data are instead factor-analysed casewise, in order to group the participants according to the similarity of their perspectives. The resulting groupings constitute the factors or perspectives produced by the sample. Relevant to the analysis of Q-sorts are the following points.

(i) Eigenvalues. The relative contribution each factor makes to explaining the total variance in the dataset is salient. The standard procedure for determining this is the eigenvalues, which are automatically produced by the software programme for each factor. It is recommended that only those factors with eigenvalues $>1$ are used in the final interpretation of 
TABLe 2: Sample characteristics $(n=23)$.

\begin{tabular}{lc}
\hline Variable & Number \\
\hline Gender & \\
Male & 14 \\
Female & 9 \\
Age & \\
51-55 & 2 \\
$56-60$ & 4 \\
61-65 & 7 \\
66-70 & 4 \\
$71-75$ & 2 \\
$>75$ & 4 \\
Marital status & \\
Single/lives alone & 18 \\
Married/cohabits & 5 \\
Professional status & \\
Professional & 6 \\
Managerial/ & 7 \\
administrative & 5 \\
Skilled/semiskilled & 4 \\
Unskilled & 15 \\
Period of time since TIA & \\
<6 months & \\
6-12 months & \\
12-18 months & \\
\hline
\end{tabular}

the data, since these will explain more of the total variance than those factors with eigenvalues $<1$ [22].

(ii) Factor Rotation. To achieve the best solution to a dataset, factor analysis software automatically rotates the factors according to the purpose of the analysis; with Q-methodology, it is recommended that this rotation ensures that participants tend to be associated with only one factor or perspective, by maximising the variance between each factor; this is known as varimax rotation.

(iii) $Z$-scores. $Z$-scores here are used as a measure of the salience of each statement to the factor on which it is loaded or associated; each statement that loads onto a factor will therefore have a $z$-score. As the $z$ score is a measure of standard deviation, a statement with a $z$-score of +3.0 , for example, would suggest that this statement is 3 standard deviations above the midpoint of the data distribution and would therefore represent a high level of agreement with the statement (towards the right-hand pole of the Qgrid).

The recommended procedure for interpreting the output from PQMethod involves combining the factor outputs, the normalised factor scores ( $z$-scores), and the statements that distinguish between the factors [22]. Individuals' narrative explanations for their choices are also used to aid to factor interpretation.

\begin{tabular}{|c|c|c|c|c|c|c|c|c|}
\hline & & & & 39 & & & & \\
\hline & & & 18 & 27 & 29 & & & \\
\hline & & 22 & 5 & 20 & 11 & 35 & & \\
\hline & & 4 & 3 & 23 & 37 & 38 & & \\
\hline & 24 & 26 & 28 & 7 & 10 & 21 & 1 & \\
\hline 30 & 16 & 33 & 9 & 34 & 19 & 32 & 31 & 14 \\
\hline 12 & 8 & 25 & 13 & 2 & 36 & 15 & 17 & 6 \\
\hline-4 & -3 & -2 & -1 & 0 & +1 & +2 & +3 & +4 \\
\hline
\end{tabular}

Figure 3: Sample of completed Q-sort grid, showing statement numbers, arranged in rank order from -4 (most unlike my own experience) to +4 (most like my own experience).

2.6.2. Results. In accordance with recommended practice, therefore, a varimax rotation was adopted, and only those factors with eigenvalues of $>1$ were included [22]. Eight factors emerged; the summary details are presented in Table 3.

Table 3 displays the 8 factors that were produced by PQMethod. In this table, each factor has been given a label that reflects the general nature of the perspective it represents (column 1). Column 2 provides information about the number of participants loading on each factor and the \% variance of the whole data-set accounted for. As a varimax rotation was used, no participant loaded onto more than one factor, and therefore, the perspectives can be considered to be discrete at this level. Column 3 represents those statements that loaded onto each factor. A statement can contribute to more than one perspective, so it is possible that any given concourse statement could appear on more than one factor; here, for example, the statement "I thought how lucky I'd been not to have a full stroke" loads negatively onto factor 5 (depression) because these respondents did not consider this statement applied to their own experience, while it also loads positively onto factor 8 (constructive optimism), because these respondents reported that they had been lucky. In this way, the simultaneous loadings onto more than one factor can be explained in the context of that factor's theme. It would not be anticipated that the statements themselves would be discrete. Column 4 records the $z$-scores associated with each statement, and hence its salience to the factor.

Factor 1: "Lack of knowledge and understanding of TIA". Five participants and five statements loaded on factor 1, which was labelled "Lack of knowledge and understanding of TIA." These statements together with the participants' narrative explanations indicated that these five respondents were either unaware that anything was happening to them, because they felt no symptoms, or that they did not realise the symptoms' significance or know what to do about them. Illustrative comments included the following:

\section{"I didn't notice any thing had happened; it was my partner who noticed that my mouth had started to droop,"}

"I knew something bad was happening, but I had no idea what I should do about it." 
TABLE 3: Factor structure of Q-sorts.

\begin{tabular}{|c|c|c|c|}
\hline Factor number and name & $\begin{array}{l}\text { Number of respondents loading on } \\
\text { factor (\% variance accounted for) }\end{array}$ & Significantly loaded concourse statements & $Z$-score \\
\hline \multirow{5}{*}{$\begin{array}{l}\text { (1) Lack of knowledge and } \\
\text { awareness of TIA }\end{array}$} & \multirow{5}{*}{$5(21)$} & $\begin{array}{l}\text { When it happened, I did not really know } \\
\text { what was happening to me }\end{array}$ & 2.170 \\
\hline & & I did not feel any different afterwards & 1.733 \\
\hline & & $\begin{array}{l}\text { I have no idea how to avoid it happening } \\
\text { again }\end{array}$ & 1.28 \\
\hline & & I was scared about the long-term effects & -0.93 \\
\hline & & $\begin{array}{l}\text { The impact of what happened went on for } \\
\text { some time }\end{array}$ & -1.46 \\
\hline \multirow{4}{*}{ (2) Life impact of TIA } & \multirow{4}{*}{$3(15)$} & $\begin{array}{l}\text { Every part of my life was affected by what } \\
\text { happened }\end{array}$ & 2.07 \\
\hline & & $\begin{array}{l}\text { Afterwards, I felt frustrated by what I } \\
\text { couldn't do }\end{array}$ & 1.815 \\
\hline & & $\begin{array}{l}\text { The impact of what happened went on for } \\
\text { some time }\end{array}$ & 1.756 \\
\hline & & My memory was affected afterwards & 1.44 \\
\hline \multirow{4}{*}{ (3) Anxiety } & \multirow{4}{*}{$3(9)$} & $\begin{array}{l}\text { I was overwhelmed with anxiety } \\
\text { afterwards }\end{array}$ & 2.35 \\
\hline & & I was scared about the long-term effects & 2.08 \\
\hline & & I couldn't sleep for worry afterwards & 2.03 \\
\hline & & I lost all confidence in my body afterwards & 1.17 \\
\hline \multirow{4}{*}{ (4) Interpersonal impact } & \multirow{4}{*}{$3(8)$} & $\begin{array}{l}\text { I felt my family was a bit irritated with me } \\
\text { afterwards }\end{array}$ & 2.11 \\
\hline & & $\begin{array}{l}\text { I felt I was a bit of a burden on my family } \\
\text { afterwards }\end{array}$ & 1.68 \\
\hline & & $\begin{array}{l}\text { Being unable to communicate afterwards } \\
\text { was upsetting }\end{array}$ & 1.564 \\
\hline & & My friends seemed to avoid me afterwards & 0.74 \\
\hline \multirow{3}{*}{ (5) Depression } & \multirow{3}{*}{$2(7)$} & I was very withdrawn afterwards & 2.30 \\
\hline & & I became very depressed after it happened & 2.065 \\
\hline & & $\begin{array}{l}\text { I thought how lucky I'd been not to have a } \\
\text { full stroke }\end{array}$ & -1.41 \\
\hline \multirow{4}{*}{$\begin{array}{l}\text { (6) Impact of physical } \\
\text { symptoms of TIA }\end{array}$} & \multirow{4}{*}{$3(6)$} & $\begin{array}{l}\text { The numbness in my face afterwards } \\
\text { really worried me }\end{array}$ & 2.08 \\
\hline & & $\begin{array}{l}\text { Being unable to communicate afterwards } \\
\text { was upsetting }\end{array}$ & 2.08 \\
\hline & & $\begin{array}{l}\text { I found the weakness in my arm after- } \\
\text { wards distressing }\end{array}$ & 0.92 \\
\hline & & $\begin{array}{l}\text { I felt I was a bit of a burden on my family } \\
\text { afterwards }\end{array}$ & 0.86 \\
\hline \multirow{4}{*}{$\begin{array}{l}\text { (7) Cognitive } \\
\text { avoidance/denial }\end{array}$} & \multirow{4}{*}{$2(4)$} & $\begin{array}{l}\text { What happened made me re-think what's } \\
\text { important to me }\end{array}$ & -0.90 \\
\hline & & I was scared about the long-term effects & -1.45 \\
\hline & & $\begin{array}{l}\text { I was thankful I had been given this } \\
\text { warning sign }\end{array}$ & -1.48 \\
\hline & & $\begin{array}{l}\text { Every part of my life was affected by what } \\
\text { happened }\end{array}$ & -1.85 \\
\hline \multirow[t]{2}{*}{ (8) Constructive optimism } & \multirow[t]{2}{*}{$2(3)$} & $\begin{array}{l}\text { I thought how lucky I'd been not to have a } \\
\text { full stroke }\end{array}$ & 2.26 \\
\hline & & $\begin{array}{l}\text { I improved my lifestyle as a result of what } \\
\text { happened }\end{array}$ & 1.79 \\
\hline
\end{tabular}


This factor highlights a lack of awareness of either the immediate or long-term significance of TIA.

Factor 2: "Life impact of TIA". The scope and enduring impact of TIA characterises factor 2. Loading on this factor were three respondents and four defining statements, including specific issues of memory loss, the general duration of the symptoms, and the TIA's impact on all aspects of the respondents' lives. For the participants clustering on this factor, the scope and long-term impact of TIA were adverse and significant, for example,

"My memory did suffer quite a bit, especially my
short-term memory. It's better now, but still hasn't
returned to how it was before. It's very infuriat-
ing,"

"The fuzziness in my head is still there after more than 6 months; I wonder whether I will ever be able to function normally again."

This factor suggests that contrary to some research, the impact, if not the physical symptoms of TIA, persists for a considerable period after the event.

Factor 3: "Anxiety". Factor three, labelled "Anxiety", comprised three respondents and 4 statements, for example,

"It was very frightening. I was really scared not just at the time, but for a long time afterwards,"

"I couldn't stop thinking about it for ages; the worry stopped me sleeping and functioning properly."

These statements, coupled with the additional narratives provided, highlight an underreported reaction to TIA. In contrast to the well-documented post-TIA depression $[9,11-$ 13], anxiety has not been widely recognised. Yet the anxiety experienced by these respondents was evidently considerable.

Factor 4: "Interpersonal Impact". Factor four, comprising 3 respondents and 4 statements, highlights the social and familial impact of TIA, especially when speech is impaired. Illustrative comments loading on this factor included the following:
"Because my main symptoms went away quite quickly, my family thought I was making a fuss about nothing, so I didn't feel I could talk to them about it,"
"My speech was a bit slurry afterwards and my family got irritated when they couldn't understand what I was saying,"
"I felt really isolated afterwards. I was so embar- rassed about my face and speech, that I couldn't go out with friends, even though everyone said they didn't notice any problems."

These experiences corroborate other research linking TIA to impaired social functioning [15].
Factor 5: "Depression". Factor five confirms depression as an enduring, significant consequence of TIA $[11,12]$. The two positively and one negatively loaded defining statements together reflect a possibly morbid reaction to the TIA, bordering on clinical depression, for example,

"I just sort of went inside myself afterwards; I didn't want to speak or be with anyone,"

"I felt so very low for ages; I couldn't pull myself out of it. I really think I should have gone to my doctor and asked for something to help me stop being so depressed".

Factor 6: "Impact of physical symptoms". Factor six confirms the physical consequences of TIA which have been noted in other research $[8,9]$. Illustrative comments included the following:

"I couldn't speak properly for about an hour after the TIA. It was probably the worst aspect of the whole experience,"

"Because I was quite weak as a result, I needed quite a bit of care. I definitely felt I was a burden on my family."

Contrary to some other research that suggests TIA symptoms typically last no longer than an hour [2], these participants reported some persistent effects, such as weakness.

Factor 7: "Cognitive avoidance". Factor seven is characterised by negativity and denial. Four defining statements negatively loaded on this factor, suggesting that the two respondents for whom this was central experience were apparently dismissive of the TIA. While it is conceivable that the TIAs in these cases actually were minor, these participants were still experiencing some physical and cognitive problems 6 months after TIA, thus suggesting that they were in denial about the reality of the situation:
"There's no point worrying about the future; what will be, will be. I can't do anything to change it,"
"I can't do anything to change what has happened or what will happen. I feel fine now, so what's to worry about?"

Factor 8: "Constructive Optimism". The final factor was characterised by two defining statements, both of which revealed a positive approach to the event, especially with regard to improving lifestyle. The two respondents loading on this factor reported feelings of relief and good fortune:

"I definitely considered myself to be lucky not to have had a stroke; it could have been a lot worse,"

"I took the advice about improving my lifestyle very seriously; I improved my diet, took more exercise and went for regular check-ups at the doctor's."

Constructive optimism is a well-documented problemsolving coping strategy [25]. 


\section{Discussion}

The factor analysis revealed eight distinct perspectives, none of which was associated with a clear clustering of participants by demographic factors. Five factors $(1,2,4,5$, and 6 ) confirmed existing research, but three (factors 3, 7, and 8 ) yielded new information about participants' anxiety and coping strategies. Each will be discussed in turn.

Factor 1 ("Lack of knowledge and understanding of TIA") highlighted these respondents' lack of awareness either of what was happening to them at the time, or of the implications of the event. Despite intensive health education campaigns intended to increase public knowledge of stroke, it appears that their impact on these participants has been limited. This could be attributable to the focus of the campaigns (on stroke rather than TIA), but the considerable body of research which has reported the ineffectiveness of recent stroke-focused health-education campaigns generally $[26,27]$ and the suboptimal level of knowledge of stroke and TIA in the population $[27,28]$ would suggest that these health education activities are not having the desired effect at any level and may need to be reconsidered. As an estimated $20 \%$ of TIA patients will go on to have a full stroke within a month, early secondary intervention measures are imperative [5]. However, lack of awareness/knowledge makes the possibility of secondary prevention difficult, since the chances of presenting for treatment are reduced [29]. These points, together with the theme of factor 1, indicate the need for a revised TIA-targeted health-education programme to increase the population's baseline knowledge, to alert them to its potential implications, and to sensitise people in highrisk categories to the likely symptoms.

Factor 2 ("Life impact of TIA") reveals the persistent adverse impact of TIA for these participants. While the longterm physical, cognitive, and psychosocial consequences for stroke patients are well-documented [30], rather less is known about the sequelae of TIA. However, the TIA research which has been conducted has reported outcomes which, while less severe, are similar to those that result from full stroke. For example, fatigue [9, 19], cognitive dysfunction [11], dysarthria [18], and quality of life [12] have all been reported for TIA patients and mirror the experiences reported by stroke patients. The core theme of factor 2 , while corroborating these research findings, also challenges the notion that TIA is transitory. Instead, it would seem that the impact, if not the physical symptoms of TIA, may persist for a considerable period after the event and confirms the need for early individualised management.

Factor 3, labelled "Anxiety," highlights a reaction to TIA that has received sparse attention. Although depression in post-TIA patients has been extensively reported $[9,11-$ 13], there is little reference to anxiety in the TIA research literature. Around 20\% of stroke patients suffer high levels of anxiety, although no clear guidelines exist for its management [31]. Since high levels of psychological distress in general, and anxiety in particular, have been noted as significant predictors of full stroke, especially in men [3234], acknowledging anxiety as a consequence of TIA would be a first stage in its proactive and targeted management.
Factor 4 ("Interpersonal Impact") suggests that a range of interpersonal relationships are adversely affected by the TIA, particularly if speech is impaired, and confirms other research linking TIA to impaired social functioning [15]. The sense of being an irritant or burden will inevitably contribute to the patient's personal stress/distress and increase the chances of subsequent stroke [32-34]. While the focus here was the TIA patient's perspective, it is well established within the stroke literature that between $25 \%$ and $54 \%$ of caregivers experience a considerable burden that may remain elevated for an indeterminate period [35]. Therefore, if these findings have any application to TIA, it would seem that both the patients and their social networks may be at risk of stress. Identifying patients and their carers who fall into this category would inform post-TIA management.

Factor 5 ("Depression") confirms other TIA research which reported persistent and significant levels of depression $[11,12]$. Evidence suggests that the probability of developing ischaemic stroke increases 3-fold in the presence of depressive symptoms [36, 37]; moreover, depression is a significant consequence of stroke that is neither well-recognised nor effectively managed [38]. Therefore, early identification and proactive management of patients with post-TIA depression is essential.

Factor 6 ("Impact of physical symptoms") corroborates other research findings that have reported the longer-term physical consequences of TIA $[8,9]$. Of interest here is the implied persistence of the symptoms, which challenges the notion that TIA symptoms typically last less than an hour [2]. It is, however, impossible to determine whether these symptoms were somatisations caused by event-induced anxiety or direct consequences of the TIA. Either way, the subjective experience merits attention within the care programme.

Factor 7, labelled "Cognitive avoidance" has as its underlying theme, negativity and denial. The two respondents who loaded on this factor appeared to attach little salience to the TIA, which could reflect their lack of awareness of its possible implications; alternatively, it is possible that the TIAs in these cases were slight and transient. However, since the respondents appeared to be experiencing some physical and cognitive impairment 6 months after TIA, it is more likely that they were denying the potential gravity of the event. Denial is a well-documented defence against stress and is central to appraisal-focused coping strategies, in which cognitive avoidance of the illness leads to minimising its seriousness [25]. While its association with TIA has not been reported, its emergence following stroke is well-established [39] and is associated with poor outcomes [40], partly because it leads to late or no presentation for treatment [41]. If these findings apply to TIA, then it might be expected that patients in denial might also postpone help-seeking activities, preventing early secondary intervention.

Factor 8 ("Constructive Optimism") indicated that the participants coped with the TIA by reconstruing it as a positive event that allowed them to consider a number of lifestyle changes that might improve their health status; it is consistent with Moos and Schaefer's classification of illness behaviours [25]. Inasmuch as coping strategies determine illness outcomes, constructive optimism offers the patient 
some measure of control, which in turn may reduce stress and offset the chances of full stroke. This response to TIA has not been previously documented and offers new possibilities for management. Within stroke research, a link has been established between low levels of pessimism and reduced incidence of stroke [42]. If a similar link between constructive optimism and positive post-TIA outcomes could be demonstrated, proactive cognitive reappraisal to encourage this coping strategy might be indicated.

There are limitations to the study. While the purposive sample of 23 participants accords with the recommendations of Q-methodology [21,22], these findings cannot be deemed definitive and, therefore, need replication. However, the sample recruited here is not dissimilar in terms of age and gender to those of other studies of population demographics of TIA patients [43] and, therefore, it might be reasonable to suppose that the experiences reported here might apply to other TIA patients. Furthermore, the resulting Q-sort stories are only as valid as the concourse statements supplied. While every effort was made to capture a broad and comprehensive range of comments and then to ensure that these were distilled by independent researchers, it is nonetheless conceivable that the spectrum of experiences was incomplete. On a more positive side, the methodology has shown itself to be a valuable aid to investigating subjective experiences in a group where communication and introspection may be difficult. It also has the added advantage of using both qualitative and quantitative methods, making the approach potentially more acceptable to a range of epistemological perspectives.

\section{Conclusions}

These factors tell eight coherent stories about patients' subjective experiences of TIA; of these, lack of knowledge of TIA, its impact on physical, cognitive, and social functioning, subsequent depression, and impaired social functioning confirm existing research. However, new themes have also emerged: deep-seated, enduring anxiety, cognitive avoidance/denial, and constructive optimism, which offer insights into the impact of TIA and emphasise the importance of targeted health education campaigns and active management. Moreover, the experiences of TIA were similar to those associated with full stroke, albeit at an attenuated level. Together, the findings highlight some possible next stages in TIA research. Firstly, the personal experiences reported here need to be investigated for their relevance to a wider TIA population; secondly, a revised and TIAfocused health education campaign needs to be trialled, especially with at-risk groups; and finally, the perspectives emerging from this study could be used as the basis for a risk-assessment scale, which following formal psychometric development could routinely be offered to post-TIA patients during the individual risk-assessment stage recommended by NICE [30]. Depending on scoring pattern, customised management programmes, including cognitive reappraisal and effective coping strategies, could be offered and their impact on rehabilitation outcomes and subsequent illness monitored.

\section{Conflict of Interests}

The author declared that there is no conflict of interests.

\section{References}

[1] J. D. Easton, J. L. Saver, G. W. Albers et al., "Definition and evaluation of transient ischemic attack: a scientific statement for healthcare professionals from the American heart association/American stroke association stroke council; council on cardiovascular surgery and anesthesia; council on cardiovascular radiology and intervention; council on cardiovascular nursing; and the interdisciplinary council on peripheral vascular disease," Stroke, vol. 40, no. 6, pp. 22762293, 2009.

[2] G. W. Albers, L. R. Caplan, J. D. Easton et al., "Transient ischemic attack - proposal for a new definition," New England Journal of Medicine, vol. 347, no. 21, pp. 1713-1716, 2002.

[3] J. Castle, M. Mlynash, K. Lee et al., "Agreement regarding diagnosis of transient ischemic attack fairly low among stroketrained neurologists," Stroke, vol. 41, no. 7, pp. 1367-1370, 2010.

[4] M. F. Giles and P. M. Rothwell, "Substantial underestimation of the need for outpatient services for TIA and minor stroke," Age and Ageing, vol. 36, no. 6, pp. 676-680, 2007.

[5] M. Fisher, "Stroke and TIA: epidemiology, risk factors, and the need for early intervention," American Journal of Managed Care, vol. 14, no. 7, pp. S204-S211, 2008.

[6] R. Luengo-Fernandez, A. M. Gray, and P. M. Rothwell, "Effect of urgent treatment for transient ischaemic attack and minor stroke on disability and hospital costs (EXPRESS study): a prospective population-based sequential comparison," The Lancet Neurology, vol. 8, no. 3, pp. 235-243, 2009.

[7] Royal College of Physicians of England and Wales, National Sentinel Stroke Audit 2006, RCP, London, UK, 2007.

[8] M. Daffertshoter, O. Mielke, A. Pullwitt, M. Felsenstein, and M. Hennerici, "Transient ischemic attacks are more than "ministrokes"," Stroke, vol. 35, no. 11, pp. 2453-2458, 2004.

[9] C. Winward, C. Sackley, Z. Metha, and P. M. Rothwell, "A population-based study of the prevalence of fatigue after transient ischemic attack and minor stroke," Stroke, vol. 40, no. 3, pp. 757-761, 2009.

[10] S. T. Pendlebury, S. Wadling, L. E. Silver, Z. Mehta, and P. M. Rothwell, "Transient cognitive impairment in TIA and minor stroke," Stroke, vol. 42, no. 11, pp. 3116-3121, 2011.

[11] I. Van Wijk, J. W. Gorter, E. Lindeman et al., "Mental status and health-related quality of life in an elderly population 15 years after limited cerebral ischaemia," Journal of Neurology, vol. 254, no. 8, pp. 1018-1025, 2007.

[12] R. S. Vohra, P. A. Coughlin, P. McShane, M. Bains, K. A. Laughlan, and M. J. Gough, "Predictors of return to work following carotid endarterectomy," British Journal of Surgery, vol. 95, no. 9, pp. 1111-1114, 2008.

[13] H. J. Luijendijk, B. H. C. Stricker, R. G. Wieberdink et al., "Transient ischemic attack and incident depression," Stroke, vol. 42, no. 7, pp. 1857-1861, 2011.

[14] C. Kessler and K. E. Thomas, "An examination of economic outcomes associated with misdiagnosis or undertreatment of TIA," The American Journal of Managed Care, vol. 15, no. 6, pp. S170-176, 2009.

[15] C. S. Anderson, K. N. Carter, W. J. Brownlee, M. L. Hackett, J. B. Broad, and R. Bonita, "Very long-term outcome after stroke 
in Auckland, New Zealand," Stroke, vol. 35, no. 8, pp. 1920 1924, 2004.

[16] G. P. Prigatano, "The importance of the patient's subjective experience in stroke rehabilitation," Topics in Stroke Rehabilitation, vol. 18, no. 1, pp. 30-34, 2011.

[17] C. Martin, G. Dellatolas, D. Viguier, L. Willadino-Braga, and G. Deloche, "Subjective experience after stroke," Applied Neuropsychology, vol. 9, no. 3, pp. 148-158, 2002.

[18] M. C. Brady, A. M. Clark, S. Dickson, G. Paton, and R. S. Barbour, "Dysarthria following stroke-the patient's perspective on management and rehabilitation," Clinical Rehabilitation, vol. 25, no. 10, pp. 935-952, 2011.

[19] V. L. Barbour and G. E. Mead, "Fatigue after stroke: the patient's perspective," Stroke Research and Treatment, vol. 2012, Article ID 863031, 6 pages, 2012.

[20] J. Ogden, Health Psychology: A Textbook, Open University Press, Maidenhead, Berkshire, UK, 2004.

[21] W. Stephenson, The Study of Behaviour: Q-Technique and Its Methodology, University of Chicago Press, Chicago, Ill, USA, 1953.

[22] J. C. Donner, "Participatory processes; an introduction to the methodology. Chapter 3," in Social Analysis: Selected Tools and Techniques, R. A. Krueger, M. A. Casey, J. C. Donner, S. Kirsch, and J. N. Maack, Eds., Social Development Papers, pp. 24-49, World Bank, Washington, DC, USA, 2001.

[23] S. Corr, "An introduction to Q methodology, a research technique," British Journal of Occupational Therapy, vol. 64, no. 6, pp. 293-297, 2001.

[24] J. Attride-Stirling, "Thematic networks: an analytic tool for qualitative research," Qualitative Research, vol. 1, pp. 385-405, 2001.

[25] R. H. Moos and J. A. Schaefer, "The crisis of physical illness: an overview and conceptual approach," in Coping with Physical Illness: New Perspectives, R. H. Moos, Ed., vol. 2, pp. 3-25, Plenum Press, New York, NY, USA, 1984.

[26] National Sentinel Stroke Audit National Sentinel Stroke Audit, 2011, http://www.hqip.org.uk/national-sentinel-stroke-audit$201 /$.

[27] L. Maasland, D. Brouwer-Goossensen, H. M. Den Hertog, P. J. Koudstaal, and D. W. Dippel, "Health education in patients with a recent stroke or transient ischaemic attack: a comprehensive review," International Journal of Stroke, vol. 6, no. 1, pp. 67-74, 2011.

[28] A. Ferris, R. M. Robertson, R. Fabunmi, and L. Mosca, "American Heart Association and American Stroke Association national survey of stroke risk awareness among women," Circulation, vol. 111, no. 10, pp. 1321-1326, 2005.

[29] N. Sprigg, C. Machili, M. E. Otter, A. Wilson, and T. G. Robinson, "A systematic review of delays in seeking medical attention after transient ischaemic attack," Journal of Neurology, Neurosurgery and Psychiatry, vol. 80, no. 8, pp. 871-875, 2009.

[30] National Institute for Clinical Excellence, Stroke: Diagnosis and initial management of acute stroke and transient ischaemic attack (TIA), NICE Clinical Guideline 68, London, UK, 2008.

[31] C. A. Campbell Burton, J. Holmes, J. Murray et al., "Interventions for treating anxiety after stroke," Cochrane Database of Systematic Reviews, vol. 12, Article ID CD008860, 2011.

[32] M. Katan, N. Nigro, F. Fluri et al., "Stress hormones predict cerebrovascular re-events after transient ischemic attacks," Neurology, vol. 76, no. 6, pp. 563-566, 2011.

[33] P. G. Surtees, N. W. Wainwright, R. N. Luben, N. J. Wareham, S. A. Bingham, and K. T. Khaw, "Psychological distress, major depressive disorder, and risk of stroke," Neurology, vol. 70, no. 10, pp. 788-794, 2008.
[34] J. G. Fiedorowicz, J. He, and K. R. Merikangas, "The association between mood and anxiety disorders with vascular diseases and risk factors in a nationally representative sample," Journal of Psychosomatic Research, vol. 70, no. 2, pp. 145-154, 2011.

[35] H. Rigby, G. Gubitz, and S. Phillips, "A systematic review of caregiver burden following stroke," International Journal of Stroke, vol. 4, no. 4, pp. 285-292, 2009.

[36] M. May, P. McCarron, S. Stansfeld et al., "Does psychological distress predict the risk of ischemic stroke and transient ischemic attack? The Caerphilly study," Stroke, vol. 33, no. 1, pp. 7-12, 2002.

[37] M. J. Bos, T. Lindén, P. J. Koudstaal et al., "Depressive symptoms and risk of stroke: the Rotterdam Study," Journal of Neurology, Neurosurgery and Psychiatry, vol. 79, no. 9, pp. 997-1001, 2008.

[38] M. L. Hackett, C. S. Anderson, A. House, and C. Halteh, "Interventions for preventing depression after stroke," Cochrane Database of Systematic Reviews, no. 3, Article ID CD003689, 2008.

[39] S. Aybek, A. Carota, F. Ghika-Schmid et al., "Emotional behavior in acute stroke: the Lausanne emotion in stroke study," Cognitive and Behavioral Neurology, vol. 18, no. 1, pp. 37-44, 2005.

[40] C. O. Santos, L. Caeiro, J. M. Ferro, R. Albuquerque, and M. L. Figueira, "Denial in the first days of acute stroke," Journal of Neurology, vol. 253, no. 8, pp. 1016-1023, 2006.

[41] L. Kitko and J. E. Hupcey, "Factors that influence healthseeking behaviors of patients experiencing acute stroke," Journal of Neuroscience Nursing, vol. 40, no. 6, pp. 333-340, 2008.

[42] H. Nabi, M. Koskenvuo, A. Singh-Manoux et al., "Low pessimism protects against stroke: the health and social support (hessup) prospective cohort study," Stroke, vol. 41, no. 1, pp. 187-190, 2010.

[43] M. S. Dennis, J. M. Bamford, P. A. G. Sandercock, and C. P. Warlow, "Incidence of transient ischemic attacks in Oxfordshire, England," Stroke, vol. 20, no. 3, pp. 333-339, 1989. 


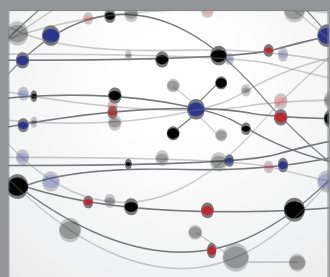

The Scientific World Journal
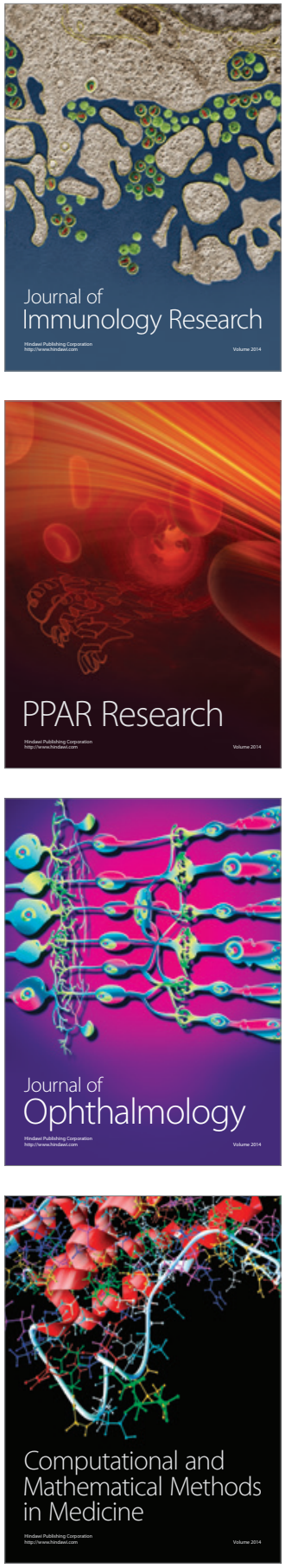

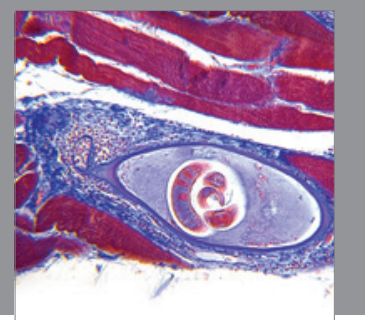

Gastroenterology

Research and Practice
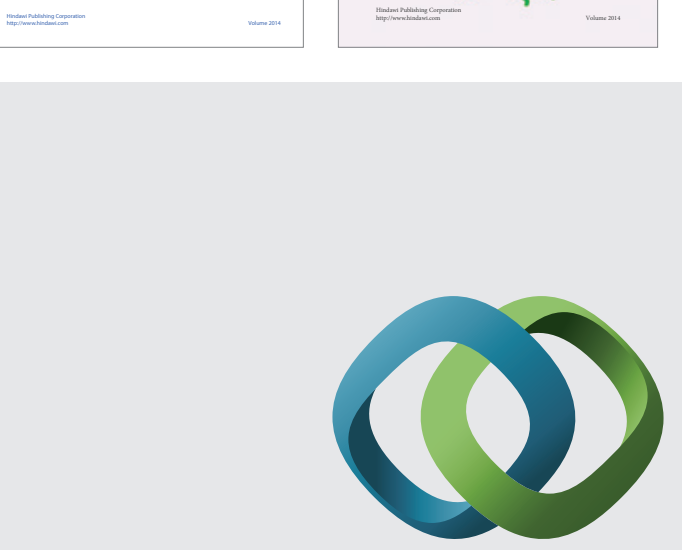

\section{Hindawi}

Submit your manuscripts at

http://www.hindawi.com
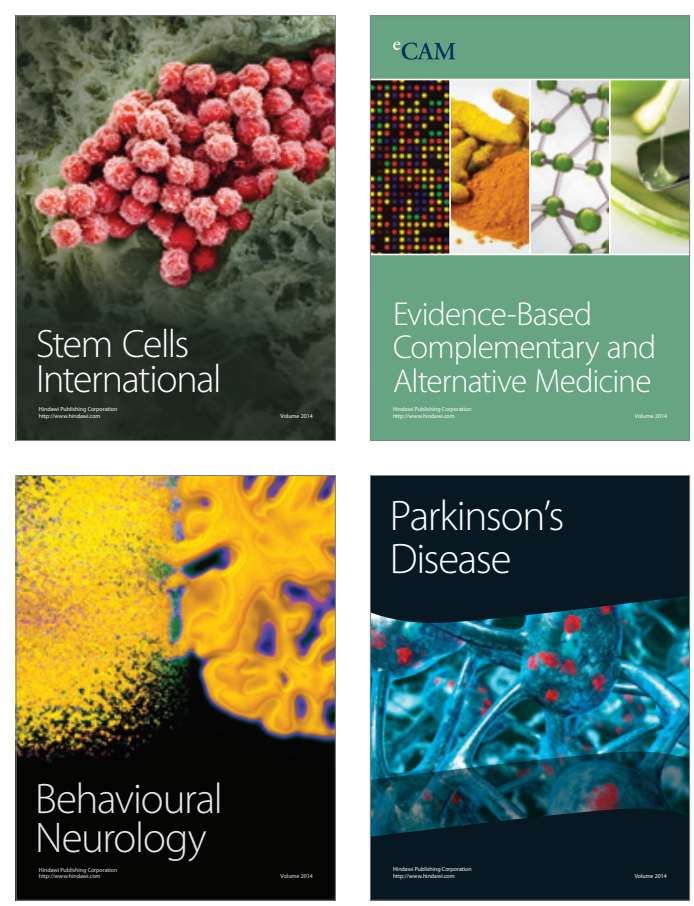

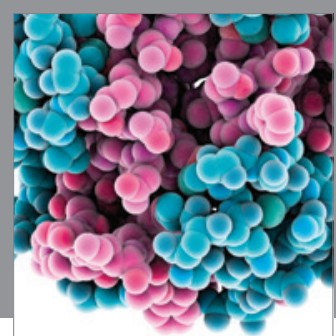

Journal of
Diabetes Research

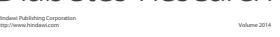

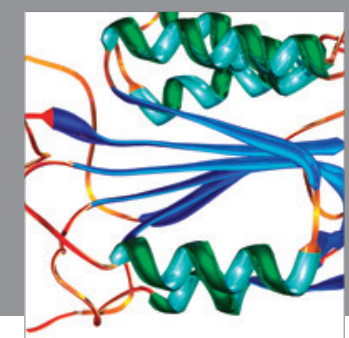

Disease Markers
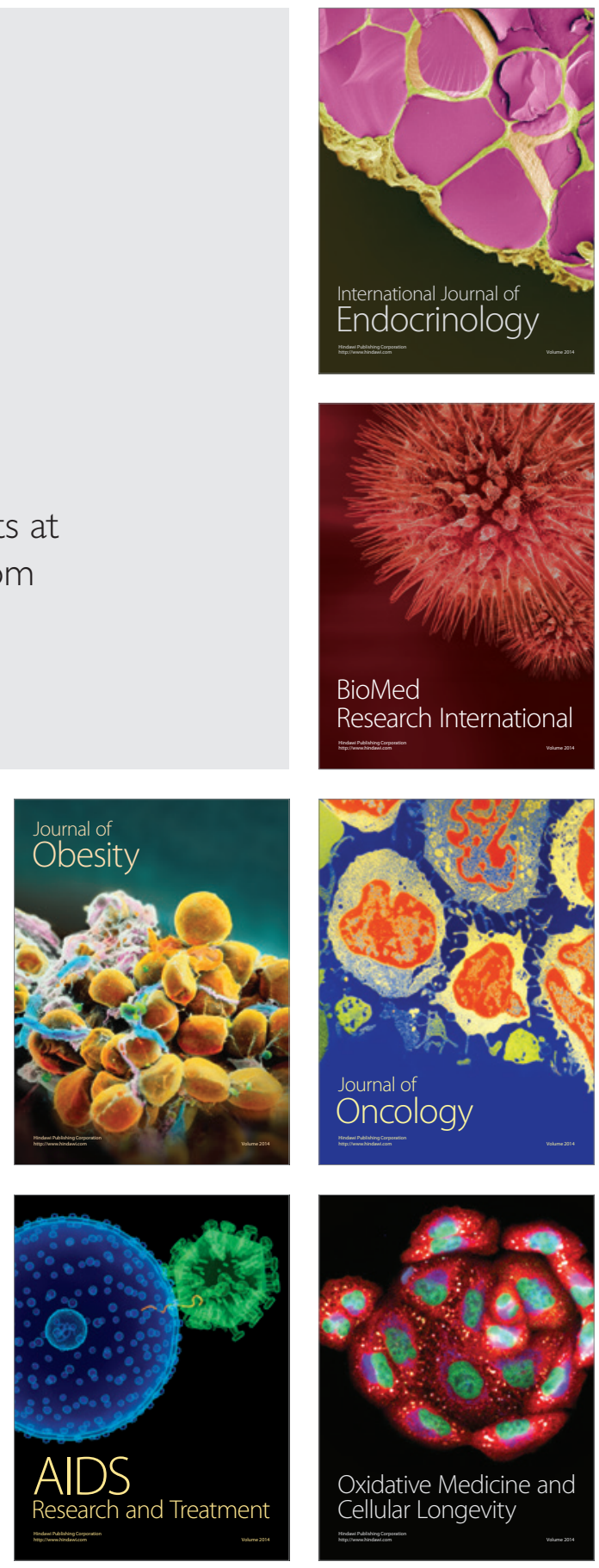